\title{
CARACTERIZAÇÃO DAS CONDIÇÕES DE VIDA DA POPULAÇÃO BENEFICIÁRIA DO PROGRAMA BOLSA FAMÍLIA EM PIRACICABA - SÃO PAULO
}

\author{
José Diego Gobbo Alves ${ }^{1}$
}

Resumo: A pobreza possui um caráter multidimensional não estando restrita à dimensão puramente econômica de insuficiência de renda. Dessa forma, este artigo traz uma reflexão sobre as famílias que fazem parte do Programa Bolsa Família (PBF), suas características individuais e, principalmente, suas condições de moradia, tendo como recorte geográfico o município de Piracicaba - São Paulo. Partiu-se da concepção de multidimensionalidade da pobreza para entender as condições socioespaciais da população, utilizando uma metodologia de levantamento de dados secundários e discussão teórica sobre o banco de dados do Cadastro Único, do PBF e seus beneficiários. Os resultados apontaram fragilidades nas condições de vida da população no município, o que reflete em moradias precárias, baixo nível de escolaridade e oportunidades de trabalho, reforçando a concepção que a transferência de renda deve vir acompanhada de outras políticas públicas para a população em estado de pobreza e extrema pobreza no Brasil.

Palavras-Chaves: Bolsa Família, Cadastro Único, Pobreza, Piracicaba.

\section{LIFE CONDITIONS' DESCRIPTION OF THE FAMILIES BENEFITED BY BOLSA FAMÍLIA PROGRAM EM PIRACICABA - SÃO PAULO}

\begin{abstract}
Poverty has a multidimensional character, is not restricted to the purely economic dimension of insufficient income. In this way, this article brings a discussion about the families that are part of the Bolsa Família Program (PBF), their characteristics, and, mainly, their housing conditions, having the municipality of Piracicaba - São Paulo as a geographical outline. It started from the concept of multidimensionality of poverty to understand the socio-spatial conditions of the population, using a methodology of collecting secondary data and theoretical discussion about the database of the Cadastro Único, the PBF, and its beneficiaries. The results indicated weaknesses in the population living conditions in the municipality, which reflects poor housing, low education, and lack job opportunities, reinforcing the view that income transfer must be accompanied by other public policies for the population in a state of disrepair poverty and extreme poverty in Brazil.
\end{abstract}

Key-Words: Bolsa Família, Cadastro Único, Poverty, Piracicaba.

\footnotetext{
${ }^{1}$ Geógrafo (Unesp - Campus Rio Claro), Mestre em Ciências Humanas e Sociais Aplicadas (Unicamp) e Doutorado do Programa de Pós-Graduação em Ambiente e Sociedade (Núcleo de Estudos e Pesquisas Ambientais - NEPAM/Unicamp). E-mail: jdgobboalves@gmail.com
} 


\section{INTRODUÇÃO}

Os pesquisadores que refletem sobre as dimensões tangenciadas pelo conceito de pobreza apontam que esta está além da insuficiência de renda das famílias, critério econômico comumente usado em alguns campos de pesquisa que versam sobre a problemática da pobreza. O conceito mais geral de pobreza engloba a ideia de privação de um sujeito ou grupo social ao acesso a algo, seja na esfera econômica, social, cultural ou espacial (KAGEYAMA; HOFFMANN, 2006). Como apontado por Costa (2017), a pobreza está também na desigualdade de distribuição socioespacial dos equipamentos públicos, das infraestruturas, dos serviços, da informação, do trabalho, da pertença e representação social e política. Sendo multidimensional (FARIAS; DIAS, 2016), a criação de políticas públicas para a superação da pobreza não implica apenas em políticas de transferência de renda para as famílias, mas também em políticas de redistribuição de direitos básicos que são garantidos pela Constituição Federal do Brasil.

Nesse sentido, a pobreza assume dimensões sociais, econômicas e espaciais que estão amalgamadas e, em um país de proporções continentais como o Brasil, ela acaba sendo aprofundada pelas discrepâncias entre as regiões brasileiras. Essas desigualdades se dão de forma inter-regionais e intraregionais, as quais estão relacionadas ao processo de acumulação vigente e sua dinâmica capitalista de apropriação de espaços (HARVEY, 2004). Tal prerrogativa reforça a necessidade de aproximação da ciência geográfica com o campo de Políticas Públicas, movimento crescente e que gradativamente consolida-se na esfera científica e nos debates públicos.

Como forma de atenuar parte dessas disparidades regionais, o Programa Bolsa Família (PBF) busca a erradicação da pobreza e da extrema pobreza no país através da transferência de renda. Mesmo que condicionalidades de educação e saúde sejam impostas, o PBF possui um caráter mais econômico em sua política, priorizando a transferência de renda para as famílias em situações de vulnerabilidade econômica. As informações das condições de vida das famílias beneficiárias do programa fornecem um panorama de parte da multidimensionalidade da pobreza no país, principalmente, ao serem analisados os dados presentes no Cadastro Único para Programas Sociais do Governo Federal (CadÚnico), plataforma que agrega informações sobre as características dos membros de cada família e de suas condições de vida e moradia.

Nesse sentido, o objetivo deste artigo é discutir as características da população beneficiária do Programa Bolsa Família (PBF) em Piracicaba - São Paulo, com ênfase nas condições das moradias das famílias e as especificidades individuais dos seus membros. Portanto, a preocupação está além dos fatores de renda que permeiam as vivências da população. Apesar de ser um estudo local, a disseminação do artigo visa instigar novos estudos fundamentais para o reconhecimento socioterritorial municipal e da política nacional de transferência de renda do Governo Federal. Além disso, os trabalhos que analisam os impactos do PBF em Piracicaba e o Cadúnico como potencial fonte de dados sobre o município ainda são incipientes e merecem serem explorados.

O interesse do autor e a elaboração deste texto surgiram a partir das discussões feitas por Maricato (2015) na qual a autora destaca que a solução para a crise e a pobreza urbana está muito além da transferência de renda realizada pelo Governo Federal. A solução parte das condições de vida das pessoas que vivem nas cidades e essas condições não melhoram exclusivamente a partir de um aumento de 
renda das famílias e, consequentemente, aumento no consumo. Assim, a partir do conhecimento prévio das potencialidades dos dados do Cadastro Único, surgiu a ideia de refletir sobre as condições de vida da população atendidas pelo PBF em Piracicaba, buscando identificar as características da população e de suas residências.

A metodologia empregada nesse estudo consistiu em levantamento e interpretação de dados secundários sobre os beneficiários do PBF em Piracicaba, além de revisão teórica sobre a importância do Cadúnico, Bolsa Família e seus resultados enquanto política pública de Estado. O mapeamento da distribuição da população beneficiária do PBF no município foi realizado no software QGIS por meio do plugin MMQGIS, a partir dos dados geoprocessados que foram fornecidos pela Secretaria Municipal de Assistência e Desenvolvimento Social (SEMADS) e referemse ao mês de março de 2021.

Há alguns entraves encontrados em relação ao acesso e a disseminação dos dados, dado o sigilo que as informações sensíveis sobre as famílias beneficiadas possuem, o que dificulta na espacialização dos dados. Contudo, parte do banco de dados pode ser consultado na plataforma do Governo Federal, além de ser possível solicitar os dados mais detalhados mediantes à apresentação de um projeto de pesquisa e assinatura de termos de confidencialidade dos dados.

Além desta seção, este texto reflete sobre a formação do Cadastro Único e a evolução do Programa Bolsa Família como uma política de transferência de renda no país. Ademais, traz uma caracterização das condições de moradia da população beneficiária do PBF no município de Piracicaba, interior do estado de São Paulo, e finaliza com as considerações finais, trazendo algumas inquietações sobre os resultados obtidos ao longo do artigo.

\section{O CADASTRO ÚNICO E O PROGRAMA BOLSA FAMÍLIA}

O Cadastro Único para Programas Sociais (Cadúnico) é um banco de dados criado pelo Governo Federal que visa concentrar as informações das famílias em estado de vulnerabilidade econômica de pobreza e extrema pobreza, caracterizando os indivíduos e as condições dos domicílios nos quais residem (MDS, 2015). Criado em 2001, o Cadastro era caracterizado pela fragmentação das informações e algumas duplicações nos dados, gerando em muitos casos, uma sobreposição de programas sociais (FARIAS; DIAS, 2016). A partir da unificação do cadastro essa situação mudou, sendo oficializado como instrumento pelo Decreto n. 6.135 de 2007:

[O CadÚnico é um] instrumento de identificação e caracterização socioeconômica das famílias brasileiras de baixa renda, a ser obrigatoriamente utilizado para a seleção dos beneficiários e integração de programas sociais do Governo Federal voltados ao atendimento desse público (BRASIL, 2007).

As informações contidas no banco de dados são utilizadas para diversos programas sociais em âmbito Federal, estadual e municipal. Portanto, o número de famílias cadastradas no Cadúnico será sempre maior do que o número de beneficiários de algum programa social em específico, como no caso do Programa Bolsa Família (PBF). Como a concessão dos benefícios se dá de forma impessoal, a 
partir das informações cadastradas, é fundamental que estas estejam sempre atualizadas e que representem as reais condições de vida das famílias (MDS, 2015).

O gerenciamento e atualização desse banco de dados se dá de forma descentralizada, sendo de responsabilidade da gestão municipal a coleta e a atualização dos dados referentes as famílias economicamente vulneráveis do munícipio. Para isso, foi criado o Índice de Gestão Descentralizada (IGD), que leva em conta diversos indicadores de qualidade e integridade dos dados municipais para avaliar a gestão do CadÚnico na esfera municipal. Como colocado por Costa (2017, p.33):

A transferência de recursos é calculada a partir de indicadores de qualidade de gestão que reflitam a qualidade e a integridade das informações constantes no Cadúnico, apuradas por meio do percentual de cadastros válidos; atualização da base de dados do CadÚnico; informações sobre o cumprimento das condicionalidades da área de educação, apuradas conforme regulamentação vigente; e as informações sobre o cumprimento das condicionalidades da área de saúde para as famílias do PBF. Para receber os recursos financeiros do IGD, o Município deve cumprir três condições: ter aderido ao Programa Bolsa Família e Cadastro Único; ser habilitado na gestão da Assistência Social; e atingir pelo menos 0,4 no valor do IGD. Quanto maior o valor do IGD, maior será o valor do recurso transferido para o Município. A transferência é feita, mensalmente, pelo Fundo Nacional de Assistência Social ao Fundo Municipal de Assistência Social.

O Cadúnico é um importante banco de dados e uma ferramenta para o entendimento territorial e, consequentemente, uma potencial fonte para a promoção de políticas públicas. As informações são diversas, tais como: escolaridade, trabalho, renda, local de residência, condições de moradia (saneamento básico, energia elétrica, número de cômodos, presença de banheiros, calçamento, tipo de construção etc.). Um geoprocessamento de qualidade espacializando essas informações, traz um diagnóstico fidedigno do território municipal. Áreas de maior ou menor concentração de famílias beneficiárias e a renda podem ser analisadas unindo às diversas outras informações como: número de escolas e hospitais, serviços, trabalho, lazer, riscos, entre outros (LOUREIRO, 2007), bem como com o extenso volume de informações geradas por meio dos Censos Demográficos.

Já o Programa Bolsa Família (PBF), transfere renda para a população em estado de pobreza e em extrema pobreza a partir de critérios econômicos, estabelecendo em contrapartida, o compromisso com a Educação e a Saúde dos membros das famílias (MDS, 2015). Essa contrapartida visa à redução da pobreza que, como já comentado, não se refere apenas às condições econômicas. Por isso, é fundamental a fiscalização no cumprimento dessas condicionalidades, a fim de buscar resultados mais concretos com a política.

O PBF foi criado em 2003 no governo do ex-presidente Luiz Inácio Lula da Silva (Partido dos Trabalhadores), a partir da unificação de vários programas sociais existentes desde o governo de Fernando Henrique Cardoso, como o Bolsa Alimentação, Bolsa Escola, Vale Gás, entre outros (CAVALCANTI e COSTA, 2013). A Figura 1 apresenta o total de famílias beneficiadas pelo PBF entre 2004 e 2021 considerando o mês de janeiro como mês de referência para cada ano. Ressaltase que diferente da variável de valor total despendido (resultado da soma de todos os meses do ano), o mesmo procedimento não foi realizado para as famílias atendidas 
pois haveria uma sobreposição das informações nas somatórias dos meses e, por isso, optou-se na utilização de um mês de referência para analisar sua evolução temporal.

Figura 1. Número de famílias atendidas pelo PBF no Brasil entre 2004 e 2021 (em milhões)

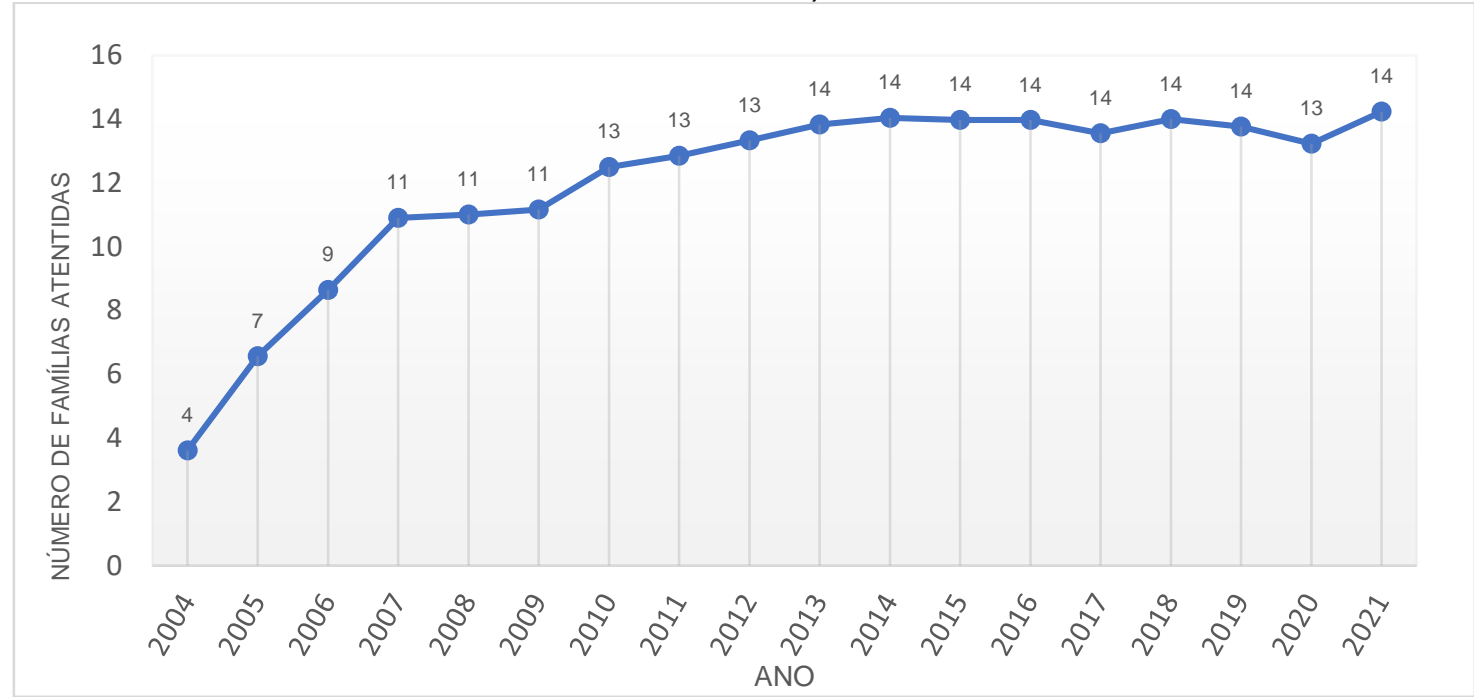

Fonte: MDS, 2021

Em outubro de 2003, foram atendidas 3,6 milhões de famílias no país, aumentando para 14,23 milhões de famílias em janeiro 2021, isto é, um aumento de mais de $400 \%$ no número de famílias atendidas. Observa-se uma estabilização no número de famílias beneficiadas a partir do ano de 2013, com uma diminuição no ano de 2020 possivelmente influenciada pela aprovação e execução do Auxilio Emergencial $^{2}$, medida econômica que visava conter a desigualdade e a intensificação da crise econômica brasileira advinda da pandemia. Considerando que o gráfico utiliza o mês de janeiro como o mês de referência, os dados indicam o impacto da pandemia no acirramento da desigualdade no país com a entrada de cerca de um milhão de famílias no PBF em um ano (2020 a 2021), justificadas pela crise sanitária vivenciada pelos brasileiros, o aumento do desemprego e o fim do Auxílio Emergencial.

A estabilidade no número de famílias beneficiárias do PBF em 2008/2009 e de 2014 em diante, suscita a hipótese de que estas tenham ocorrido por razões diferentes. No ano de 2008, a estabilidade pode ter sido resultado de um maior nível da atividade produtiva nacional, o que acarretou à expansão do emprego e, consequentemente, a redução da procura de pessoas/famílias ao PBF. Já em 2014, momento de crise da economia brasileira, a estabilidade no número de beneficiários poderia estar vinculada a um maior controle e fiscalização dos cadastrados realizados pelo governo federal, o que pode ter levado a suspensão de novos benefícios.

Já em relação a dimensão espacial das famílias atendidas pelo PBF, a Figura 2 a seguir apresenta o número de famílias atendidas pelo Programa em cada estado brasileiro nos anos de 2004 e 2021, também tendo como referência o mês de janeiro dos respectivos anos.

\footnotetext{
${ }^{2}$ Ressalta-se que as famílias atendidas pelo PBF estavam automaticamente cadastradas na política de Auxílio Emergencial, ao passo que no período que a família estava recebendo as parcelas do Auxílio Emergencial, o PBF ficou congelado, havendo, portanto, uma troca automática das famílias entre os programas.
} 
Figura 2. Número de famílias atendidas pelo PBF nos estados brasileiros entre 2004 e 2021 (em milhões)

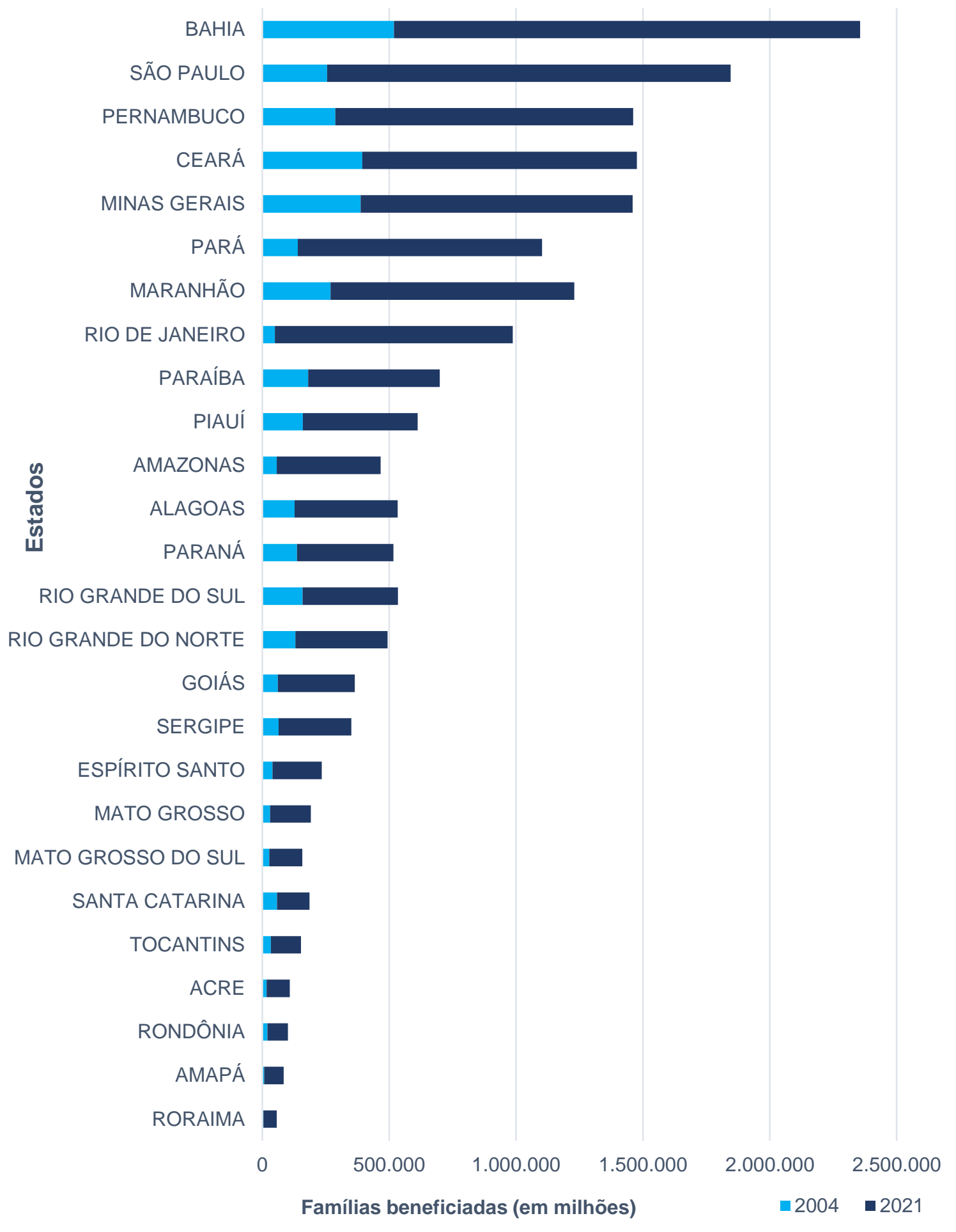

Fonte: MDS, 2021

Os dados mostram que o estado da Bahia é o estado que possui o maior número de famílias atendidas em 2021, situação encontrada também para o ano de 2004. O significativo aumento no número de famílias beneficiadas no estado da Bahia justifica-se pelo alto grau de desigualdade social e o grande número de população em estado de vulnerabilidade econômica, sobretudo em estado de extrema pobreza, 
desigualdade socioeconômica que vem diminuindo nos últimos anos, mas que ainda está presente no estado (SOUZA; OSÓRIO, 2012; SOUZA; COUTO, 2015). O aumento de famílias atendidas no estado foi significativo, cerca de $254 \%$, e segue a tendência encontrada em todos os estados brasileiros. Contudo, os estados que apresentaram os maiores aumentos no número de famílias atendidas no período foram nos estados do Rio de Janeiro (1.777\%), Roraima (1.027\%) e Amapá (217\%). Tais dados indicam um tema de pesquisa importante de ser explorado para explicar tais aumentos dentro do contexto nacional e global da dinâmica e crise capitalista. 2020.

A Figura 3 apresenta o total de valores destinado para o PBF entre 2004 e

Figura 3. Total de valores despendido pelo Governo Federa para o PBF (em bilhões de $R \$$ ) entre 2004 e 2020

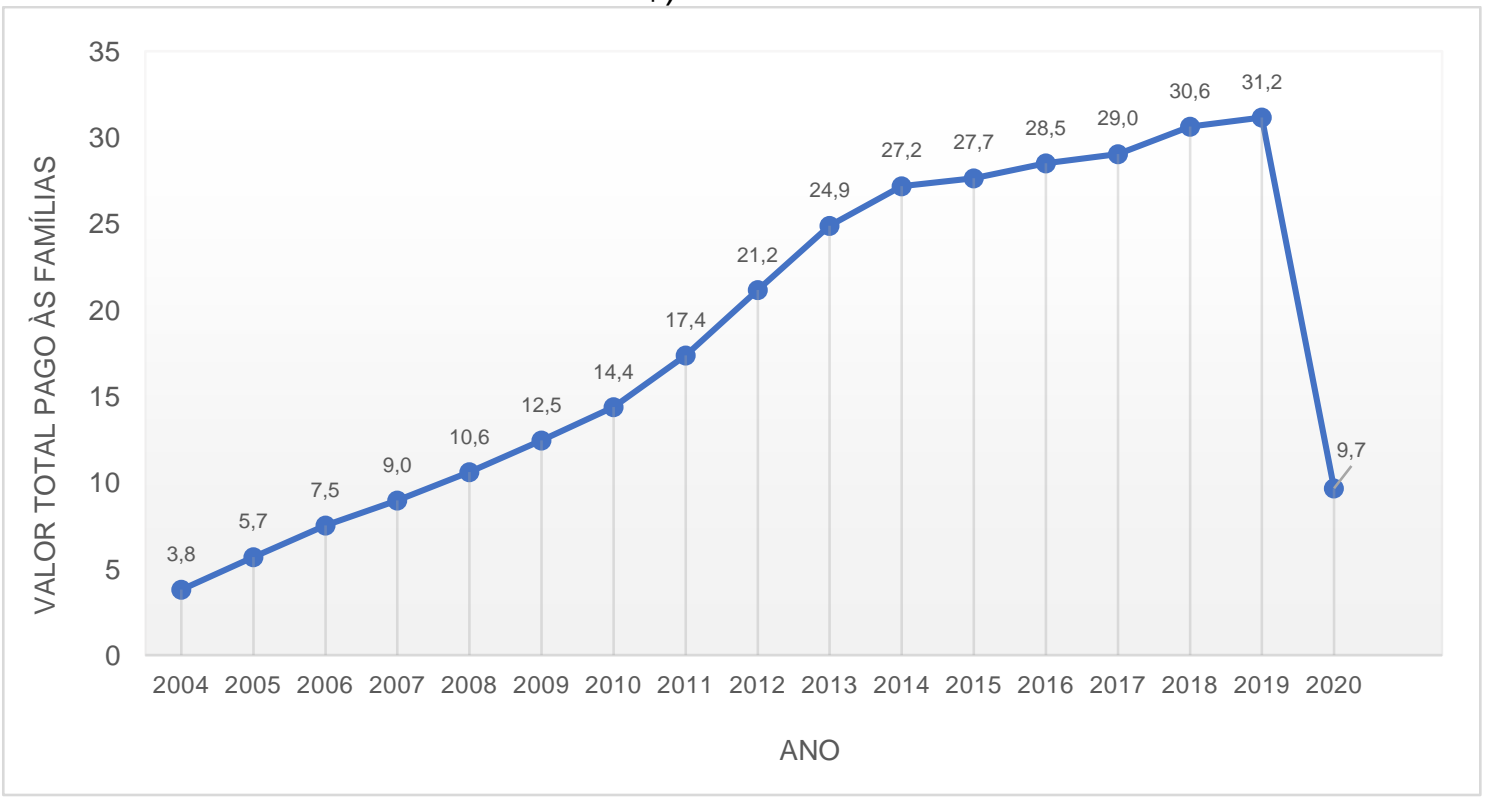

Fonte: MDS, 2021

O valor despendido pelo Governo Federal em 2003 foi de cerca de $\mathrm{R} \$ 570$ milhões, contabilizando os meses de outubro a dezembro. Em 2004, o total foi para $\mathrm{R} \$ 3,8$ bilhões e, comparando com o ano de 2019, que foram despendidos mais de $\mathrm{R} \$ 31,2$ bilhões, houve um aumento de mais de $\mathrm{R} \$ 27$ bilhões para subsidiar o PBF. Isto é, um aumento de mais de $900 \%$ no valor transferido para a população em estado de pobreza e extrema pobreza. $\mathrm{O}$ ano de 2020 foi um ano atípico na linha histórica do valor dependido, pois como mencionado anteriormente, o valor pago pela política de Auxílio Emergencial substituiu o valor do PBF nos meses ao qual a política estava vigente, logo o valor despendido pelo Governo Federal no ano de 2020 para o PBF foi menor dada a transferência de recursos para a outra política.

Considerado a estimativa feita pelo IPEA ${ }^{3}$, em que a cada $R \$ 1,00$ gasto pelo Governo Federal para o PBF há um incremento de $\mathrm{R} \$ 1,70$ na economia, o PBF gerou em 2019 um incremento de mais de $\mathrm{R} \$ 53$ bilhões. Esse valor aumentaria se 0 Governo investisse mais no PBF, atualmente o investimento é de $0,4 \%$ do total PIB. A dimensão espacial do valor destinado para os estados brasileiros pode ser

\footnotetext{
3 Informações disponíveis em: http://www.valor.com.br/brasil/3305466/ipea-cada-r-1-gasto-com-bolsa-familia-adiciona-r178-ao-pib.
} 
observada na Figura 4. Para a composição do mapa, foram utilizados os dados referentes aos anos de 2004 e 2019, pois como o PBF foi iniciado no final de 2003, não seria possível analisar o valor total destinado ao longo de um ano utilizando o ano de criação. Ademais, como o ano de 2020 possuiu uma queda significativa no valor total destinado aos estados dada a criação do Auxílio Emergencial, o ano de 2019 é o que oferece a melhor padronização dos dados para a análise comparativa.

Figura 4. Valor total destinado aos estados brasileiros por meio do Programa Bolsa

Família em 2004 e 2019

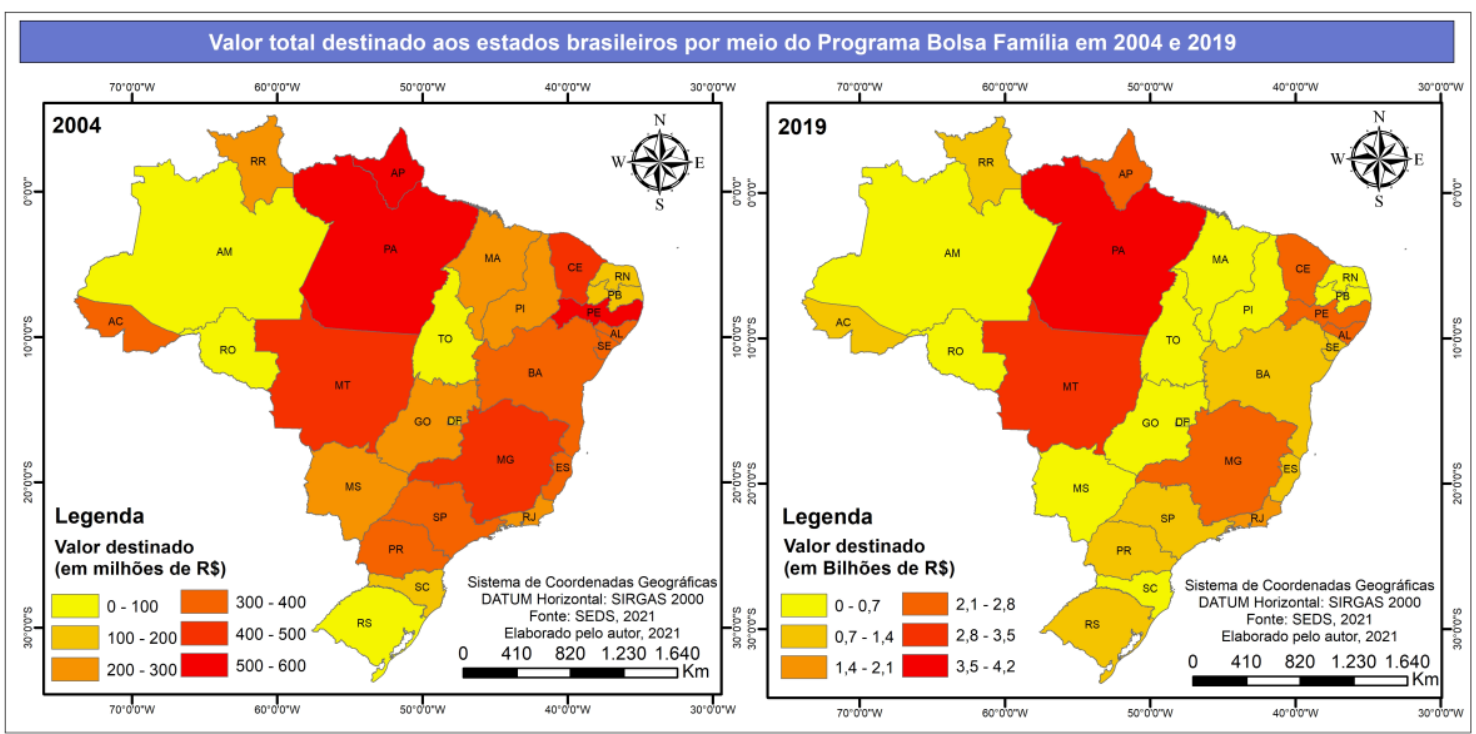

Fonte: SEDS, 2021

Observa-se um aumento substancial no valor destinado aos estados, ao passo que enquanto em 2004, o valor destinado era na casa dos milhões de reais, em 2019 aumentou para bilhões de reais em alguns estados. Espacialmente, há uma tendência de distribuição desigual dos recursos destinados para cada estado, porém, há uma permanência de estados que possuem maiores valores recebidos pelo do PBF, tais como Pará, Mato Grosso, Amapá, Ceará, Pernambuco e Minas Gerais. Esta heterogeneidade na distribuição de recursos está presente em ambos os anos e, não necessariamente, correspondem ao número bruto de famílias atendidas como mostrado anteriormente na Figura 02, caso como os dos estados da Bahia e de São Paulo são exemplos. Estes dados indicam um problema importante de ser investigado de modo mais aprofundado em outros trabalhos, visando identificar as causas e os efeitos dessa desigualdade para a superação da pobreza.

De modo geral, os principais interesses do Programa são i. o combate à desigualdade de renda e diminuição da pobreza; ii. a redução na frequência escolar para crianças e jovens de até 17 anos e, consequentemente, a redução da evasão escolar; iii. a diminuição no trabalho infantil; e iv. o aumento da segurança alimentar (CAVALCANTI; COSTA; SILVA, 2013).

O PBF agrega quatro benefícios nos quais podem ser combinados de acordo com as características das famílias, implicando em valores diferentes por família. Os valores dos benefícios, bem como o mínimo de renda per capita de cada membro de uma família descritos a seguir, são os estabelecidos pelo Governo Federal para o ano de 2018.0 primeiro é o Benefício Básico, destinado apenas àquelas famílias em estado de extrema pobreza e o valor varia para que todos os membros tenham uma renda mensal acima de $\mathrm{R} \$ 85,00$. O segundo é o Benefício Variável, destinado às 
famílias em estado de pobreza e de extrema pobreza que tenham gestantes, nutrizes, crianças e adolescentes de até 15 anos de idade, sendo pago $R \$ 39,00$ (sendo concedido no máximo 05 benefícios variável) (MDS, 2015).

O terceiro é o Benefício Variável vinculado ao Adolescente (BVJ), destinado às famílias com jovens entre 15 e 17 anos que frequentam a escola, o valor é de $R \$$ 45,00 e só é concedido dois BVJ por família. O último é o Benefício para a superação da Extrema Pobreza, destinado as famílias que, mesmo recebendo os outros tipos de benefícios, os membros não atingem o valor mínimo de $\mathrm{R} \$ 85,00$ per capita. Assim, o valor ganho varia para que todos os membros possuam o valor mínimo de $\mathrm{R} \$ 85,00$ per capta (MDS, 2015).

O PBF contribui nos últimos anos para a redução da pobreza (15\%) e da extrema pobreza (25\%) o que representa cerca de 6,6 milhões de pessoas que saíram da pobreza (3,4 milhões de pessoas) ou da extrema pobreza (3,2 milhões de pessoas) (SOUZA, et al., 2019). Apesar desse resultado positivo e do aumento da cobertura no atendimento de famílias em estado de vulnerabilidade econômica, o entrave referente ao valor pago ainda permanece, pois cada família acaba recebendo em média $\mathrm{R} \$ 180,00$, valor ainda muito baixo para que se tenha mudanças estruturais mais efetivas (SOUZA, et al., 2019). Além disso, o PBF contribuiu para o aumento do consumo e da qualidade dos bens duráveis nas residências, aumentando o bem-estar e melhorando o cotidiano da população (RAVAIOLI, 2019).

Em relação as condicionalidades (educação e saúde), o PBF estabelece que as crianças menores de 07 anos devem estar com o calendário de vacinação em dia e ter acompanhamento médico sobre seu crescimento e desenvolvimento. Além disso, as gestantes devem fazer o acompanhamento médico estabelecido pelo calendário do Ministério da Saúde (MDS, 2015).

Já em relação à Educação, todas as crianças e adolescentes entre 06 e 15 anos de idade em que as famílias são beneficiadas pelo PBF, devem estar matriculados na escola e ter frequência mínima de $85 \%$. Já os jovens de 15 a 17 anos, devem estar matriculados e ter frequência mínima de 75\% (MDS, 2015).

A importância dessa condicionalidade se dá, pois, o tempo despendido na escola, pode aparecer como uma barreira para a frequência desses alunos, já que pressupõe deixar de realizar trabalhos remunerados e não-remunerados comum entre as crianças e jovens com rendas mais baixas (GLEWWE; KASSOUF, 2008).

Segundo as pesquisas de Fahel, Moraes e França (2011), o PBF aumenta a matrícula de crianças e adolescentes beneficiários do programa nas escolas, principalmente, da população negra, moradores de áreas rurais e adolescentes do sexo masculino que são os grupos que possuem maior abandono e taxa de reprovação escolar. O mesmo resultado é obtido por Glewwe e Kassouf (2008) que analisaram os Censos Escolares até 2005 e encontraram um aumento na matrícula e uma redução na taxa de abandono escolar logo no começo do Programa.

O PBF é envolto de críticas que não são fundamentadas nos dados disponíveis e reverberam em um estigma criado sobre a população beneficiária. O primeiro deles é a ideia de que as famílias beneficiárias do programa deixam de trabalhar voluntariamente para viver apenas com a renda do PBF. Um mito que precisou e precisa ser desconstruído, resultando na inclusão de um item na cartinha do Bolsa Família, criada pelo Ministério do Desenvolvimento Social, que discute sobre esse tema, mostrando que as famílias que fazem parte do programa continuam a trabalhar e tiram sua renda principal desta ocupação (MDS, 2015).

Outra crítica vem da partidarização do programa pelo Partido dos Trabalhadores (PT). Os críticos alegam que se trata de uma política de Estado e não 
exclusiva de um único partido. Porém, tal associação é comum, principalmente, pelas melhoras na renda das famílias beneficiadas pelo programa nos governos petistas.

\section{A POPULAÇÃO BENEFICIÁRIA DO PROGRAMA BOLSA FAMÍLIA EM PIRACICABA - SÃO PAULO}

Piracicaba é um município localizado no interior do estado de São Paulo, fundado em $1^{\circ}$ de agosto de 1.767, possui uma área de $1.378,50 \mathrm{~km}^{2}$, tendo a área urbana 228,04 $\mathrm{km}^{2}$ e a área rural de $1.150,46 \mathrm{Km}^{2}$ (IPPLAP, 2015). Possui uma população de, aproximadamente, 397 mil habitantes (IBGE, 2018). É caracterizado pela sua importância regional, dado sua centralidade na Aglomeração Urbana de Piracicaba institucionalizada em 2012 (EMPLASA, 2017). O mapa a seguir (Figura 5) apresenta a localização do município e a sua mancha urbana.

Figura 5. Localização do município de Piracicaba - São Paulo

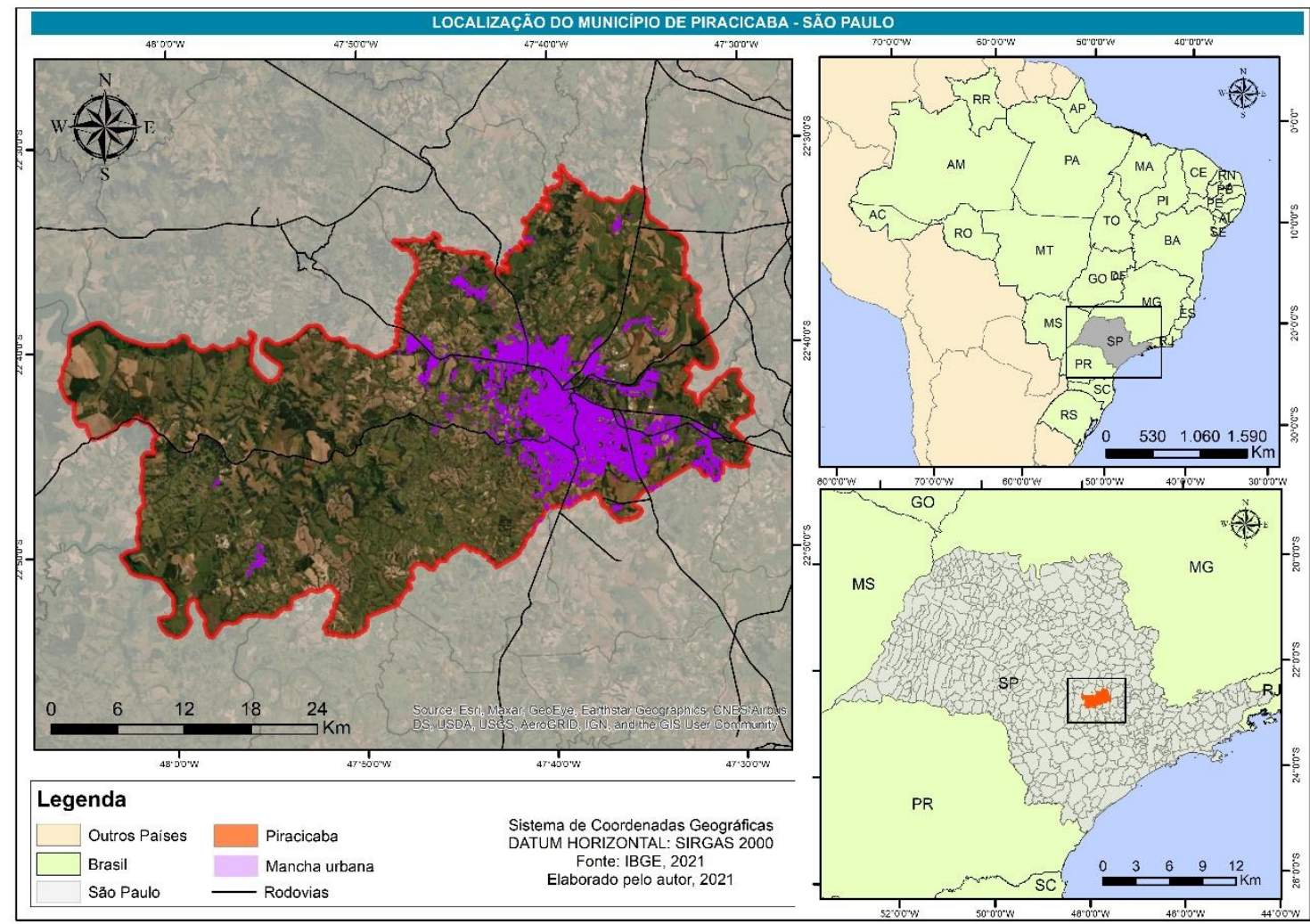

Fonte: IBGE, 2021. Elaborado pelo autor, 2021

O desenvolvimento econômico da cidade sempre esteve voltado à agricultura, principalmente, a agricultura de cana-de-açúcar. Atualmente a cidade comporta um parque industrial diversificado destacando-se na cidade os setores metalúrgicos, mecânico, agroindústrias, elétrico, laticínios, papel e celulose, têxteis e alimentícios. O setor de serviços é de grande importância para a economia da cidade, localizado na área central, bem como centros e corredores comerciais dos bairros.

Estudos realizados anteriormente (ALVES, 2019), indicam que a área urbana é caracterizada por uma forte especulação imobiliária, com a presença de vazios urbanos e um crescimento disperso e fragmentado da mancha urbana, o que torna as distâncias a serem percorridas cada vez maiores. Além disso, há uma concentração 
da população de menor renda nas áreas norte e sudoeste da cidade, áreas que estão em crescimento espacial disperso, o que impacta justamente a população de menor renda.

Em relação ao Programa Bolsa família, o gráfico a seguir (Figura 6), apresenta o número de famílias atendidas entre 2004 e 2021 no município.

Figura 6. Número de beneficiários do Programa Bolsa Família em Piracicaba entre os anos de 2004 e 2021

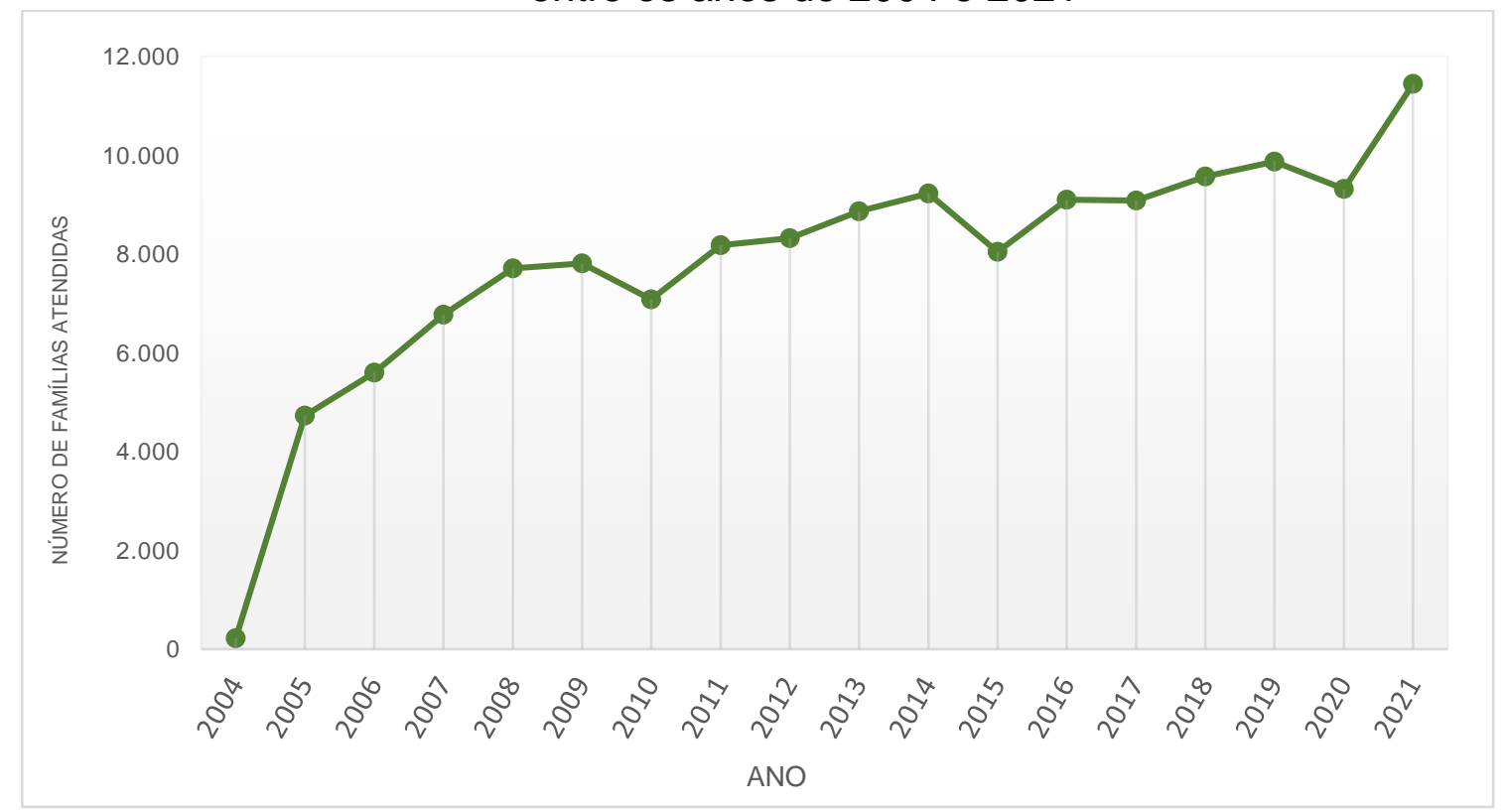

Fonte: Matriz de Informação Social, 2018

No ano de 2005, em Piracicaba, havia 4.725 famílias beneficiadas pelo PBF, em 2021 o número de famílias mais que dobrou, passando para 11,4 mil famílias beneficiadas, um aumento de $142 \%$. Entretanto, observa-se pelo gráfico que esse aumento não se deu de forma regular ao longo dos anos. Apesar do aumento a partir de 2015, nota-se uma estabilidade entre o número de famílias beneficiadas entre os anos de 2015 e 2020 (com uma ligeira queda entre 2016 e 2017). Tal estabilidade se deu pelo momento de crise política, institucional e econômica que o país enfrenta, desestabilizando alguns dos programas principais de transferência de renda e de construção de infraestruturas fazendo com que não tenha tido um aumento mais progressivo de famílias beneficiadas. Contudo, no mês de janeiro do ano de 2021 há um aumento importante possível de ser observado sendo, até então, o ano que mais possui beneficiados no PBF. Infere-se que esse aumento se deu por três fatores: a) a crise econômica do país e o aumento do desemprego no município de Piracicaba; b) a crise sanitária da pandemia do Coronavírus e, c) o fim do Auxílio Emergencial e o aumento da necessidade das famílias por algum auxílio econômico.

Comparativamente, em 2017 havia 26 mil famílias cadastradas no Cadastro Único para Programas Sociais do Governo Federal no município, porém cerca de 9 mil famílias foram atendidas, representando cerca de $34,6 \%$ do total de pessoas cadastradas (MATRIZ DE INFORMAÇÃO SOCIAL, 2018; MDS, 2018). Portanto, como a cobertura do PBF é sempre menor do que o número de famílias cadastradas no CadÚnico, o aumento de famílias atendidas no município é resultado também de um aumento recente de famílias em estado de vulnerabilidade econômica. 
O gráfico a seguir (Figura 7) apresenta o valor total (em milhões de $R \$$ ) repassado pelo Governo Federal para o atendimento das famílias beneficiadas pelo PBF no município de Piracicaba entre 2004 e 2020.

Figura 7. Valor total repassado anualmente entre os beneficiários do PBF entre 2004 e 2020 em Piracicaba - São Paulo

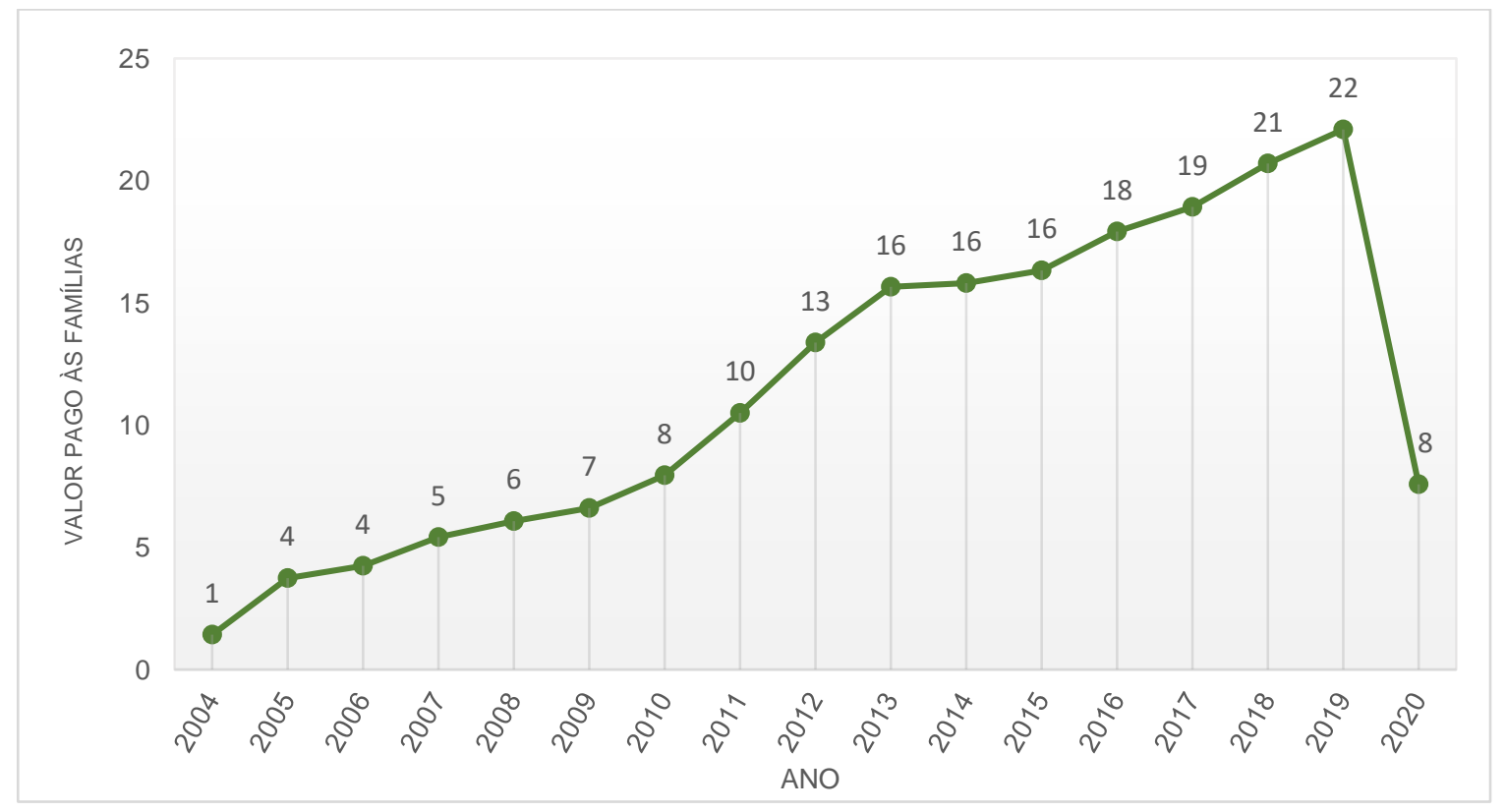

Fonte: Matriz de Informação Social, 2021

Assim como o aumento no número de famílias atendidas, os repasses do Governo Federal também aumentaram. Em 2004, foram destinados cerca de $R \$ 1,5$ milhões para as famílias atendidas no município. Em 2019, foram repassados cerca de $R \$ 22$ milhões. Assim como observado em nível nacional, no ano de 2020 também é possível observar uma queda no valor total pago as famílias piracicabana por meio do PBF, justificado pela transição temporária entre o PBF e a política de Auxílio Emergencial.

Segundo os dados coletados no Ministério do Desenvolvimento Social para o ano de 2017, havia 9.343 famílias beneficiárias do Programa Bolsa Família (PBF) no município de Piracicaba. Deste total, 93,3\% residiam na área urbana e 4,9\% na área rural. As condições da moradia das famílias nas áreas urbanas e rurais eram diversas, o que concretiza a heterogeneidade da população atendida pelos programas sociais (MDS, 2018).

Tratando da faixa de renda familiar per capita das famílias beneficiadas em $2017,69,7 \%$ estão na faixa de até $R \$ 85,00 ; 23,5 \%$ entre $R \$ 85,01$ até $R \$ 170,00$ e $6,90 \%$ entre $R \$ 170,01$ até $1 / 2$ Salário-Mínimo. Tais dados reafirmam a condição de fragilidade econômica que essas famílias se encontram, intensificadas pelas condições de moradia, oferta de serviços, localização de residência, segregação espacial, entre outros agravantes da manutenção desse problema. Vale lembrar que as famílias com renda per capita de até $\mathrm{R} \$ 85,00$ são consideradas em estado de extrema pobreza, o que mostra que quase $70 \%$ das famílias atendidas no município estão nessa condição. A Figura 8 a seguir corrobora para a discussão ao apresentar o valor médio pago às famílias por meio do PBF em Piracicaba. Assim como observado no número de famílias e no valor destinado pelo Governo Federal ao 
município, o valor médio pago às famílias também aumentou significativamente desde a criação do programa, ao passo que pequenas variações anuais são observadas. Apesar do valor ter aumentado nos últimos anos, o estado de pobreza e extrema pobreza que as famílias beneficiadas se encontram demonstra que tem muito a ser feito no que tange à política de erradicação da pobreza.

Figura 8. Valor médio pago às famílias por meio do PBF entre 2004 e 2021 em Piracicaba - São Paulo.

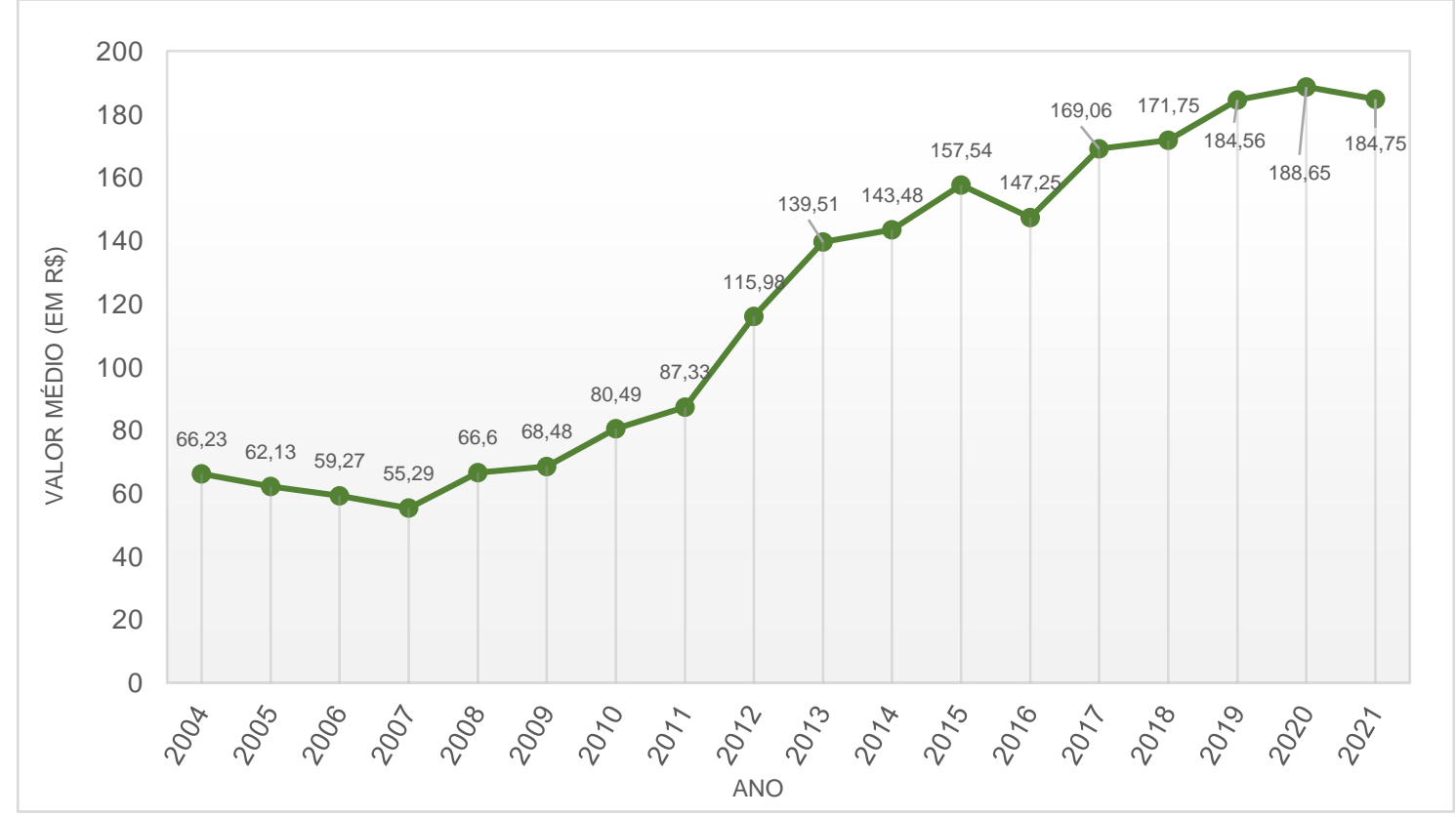

Fonte: Matriz de Informação Social, 2021

Em relação à distribuição espacial das famílias beneficiárias do PBF, a Figura 9 apresenta o local de residências das famílias na cidade de Piracicaba. Os dados foram fornecidos pela Secretaria Municipal de Assistência e Desenvolvimento Social (SEMADS) do município de Piracicaba e refere-se ao mês de março de 2021.

Observa-se, por meio do mapa, que há uma distribuição desigual das famílias beneficiárias pelo PBF na cidade. Há uma concentração de famílias nas áreas Norte e Sudoeste da cidade, áreas que historicamente acomodam grupos sociais de menor renda e que compreendem os bairros Jardim Gilda, Bosque dos Lenheiros e Vila Sonia (quadrante Norte) e Vila Cristina, Paulista e Novo Horizonte (Quadrante Sul). O resultado já era esperado, ou seja, o de áreas de menor renda congregarem maior número de famílias beneficiadas pelo $\mathrm{PBF}$, porém, os dados corroboram para a discussão sobre o processo de segregação urbana presente na cidade. Ambas as áreas em destaque, são áreas em franca e recente expansão urbana, com a criação de novos loteamentos urbanos distantes do centro urbano consolidado, mesmo com a presença de vazios urbanos na cidade (ALVES; BRAGA, 2017a; 2017b), o que indica que a cidade está sendo produzida segregando grupos em estado de vulnerabilidade socioeconômica.

A distribuição espacial das famílias beneficiarias instiga estudos futuros acerca da relação entre o local de moradia e a disponibilidade de infraestruturas e serviços públicos na cidade. Haja vista que a pobreza possui um caráter multidimensional, essa correlação espacial é importante de ser explorada em estudos futuros para contribuir 
para o campo da Geografia Urbana e na formulação de políticas públicas urbanas eficazes contra a pobreza e a extrema pobreza.

Figura 9. Distribuição espacial das famílias beneficiárias do PBF em Piracicaba

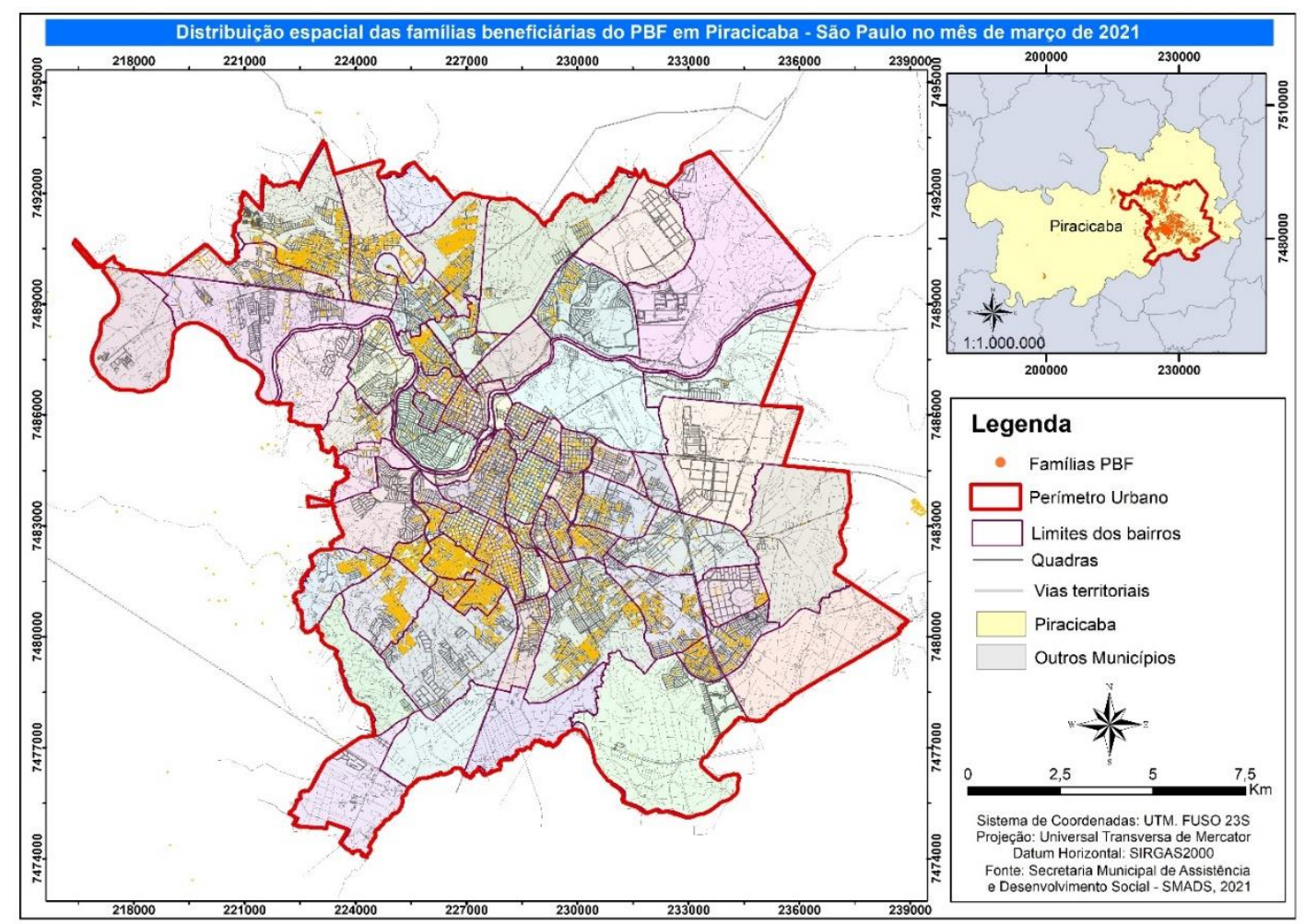

Fonte: SMDS, 2021 - Elaborado pelo autor, 2021

O CadÚnico oferece um perfil das pessoas atendidas pelo PBF. Assim, Piracicaba em 2017, havia cerca de 29 mil pessoas atendidas pelo programa, sendo $58,3 \%$ do sexo feminino e $41,7 \%$ do sexo masculino. Seguindo critérios de autodeclaração, $48,3 \%$ das pessoas se autodeclararam branca; $10,5 \%$ se autodeclararam preta; $0,2 \%$ amarela; $40,8 \%$ parda e 0,01\% indígena (MDS, 2018).

A Tabela 1 a seguir apresenta o grau de instrução das pessoas com mais de 18 anos pertencentes às famílias beneficiadas pelo PBF em Piracicaba.

Optou-se por um recorte etário de pessoas com mais de 18 anos, pois, o número de crianças e adolescentes tende a superestimar o grau de instrução, desde o "sem instrução" até o "Médio Completo", já que essas crianças e adolescentes estão ainda em idade escolar.

Dito isso, $37,7 \%$ das pessoas pertencentes às famílias atendidas pelo PBF possuem o ensino fundamental incompleto, seguido por Médio Completo com 22,8\%. Esses dados mostram a importância da obrigatoriedade da frequência escolar de crianças e adolescentes que a política condiciona, principalmente visando aumentar o grau de instrução das famílias.

Considerando as pessoas que não concluíram o Ensino Médio, o número salta para $75,8 \%$ das pessoas acima de 18 anos pertencentes ao PBF. Número extremamente elevado, mas que mostra a realidade de muitos brasileiros, principalmente das pessoas que possuem renda mais baixas, apesar de uma mudança promissora quanto à alfabetização. 
Tabela 1. Grau de instrução das pessoas com mais de 18 anos beneficiadas pelo PBF

\begin{tabular}{|c|c|c|c|c|c|c|c|}
\hline \multirow[b]{2}{*}{ Sexo } & \multicolumn{6}{|c|}{ Grau de Instrução } & \multirow[b]{2}{*}{ Total } \\
\hline & $\underset{\text { instrução }}{\text { Sem }}$ & $\begin{array}{l}\text { Fundamental } \\
\text { incompleto }\end{array}$ & $\begin{array}{c}\text { Fundamental } \\
\text { completo }\end{array}$ & $\begin{array}{c}\text { Médio } \\
\text { incompleto }\end{array}$ & $\begin{array}{c}\text { Médio } \\
\text { completo }\end{array}$ & $\begin{array}{c}\text { Superior } \\
\text { incompleto } \\
\text { ou mais }\end{array}$ & \\
\hline Masculino & $6,60 \%$ & $39,10 \%$ & $15,90 \%$ & $17,40 \%$ & $19,80 \%$ & $1,20 \%$ & $100,00 \%$ \\
\hline Feminino & $5,30 \%$ & $37,10 \%$ & $15,50 \%$ & $16,60 \%$ & $24,30 \%$ & $1,30 \%$ & $100,00 \%$ \\
\hline Total & $5,70 \%$ & $37,70 \%$ & $15,60 \%$ & $16,80 \%$ & $22,80 \%$ & $1,30 \%$ & $100,00 \%$ \\
\hline
\end{tabular}

Fonte: Ministério do Desenvolvimento Social, 2018

Além disso, as mulheres apresentam os menores índices quanto à falta de instrução (fundamental incompleto e completo e médio incompleto) se comparada com os homens além de apresentarem um índice um pouco maior de conclusão do ensino médio do que os homens (cerca de 5\%) (MDS, 2018).

Em relação ao tipo de moradia das famílias, 96,8\% residem em um domicílio particular permanente, enquanto, $0,31 \%$ residem em domicílios particulares improvisados e $1,16 \%$ residem em domicílios coletivos (1,8\% não informaram). $O$ alto índice de domicílios particulares, pode ser explicado pelas políticas de moradias para a população nos âmbitos Federal, Estadual e Municipal, principalmente nos dois primeiros, além da autoconstrução em áreas inapropriadas para a habitação (MDS, 2018).

Quanto as características dos domicílios, 95\% destes possuem banheiro (cômodo), enquanto 1,1\% não possuem e 3,2\% não responderam. Entretanto, quando analisamos a forma de escoamento sanitário, observa-se que há uma diminuição para $89 \%$ das famílias que possuem ligação com uma rede coletora de esgoto ou pluvial, ao mesmo tempo em que $11 \%$ das famílias possuem um escoamento sanitário impróprio ou inexistente (fossas sépticas, fossa rudimentar, vala a céu aberto, direto em rios e lagos). Isto é, cerca de 1.000 famílias não dispõem de coleta de esgoto sanitário, acarretando impactos sociais (quanto a sua formação como cidadão); ambiental (poluição e contaminação do solo e dos cursos d'água) e para a saúde (doenças causadas pelo contato com esses fluídos e proliferação de epidemias) (MDS, 2018).

Situação semelhante ocorre com a coleta de lixo, $85,7 \%$ das famílias têm seu lixo coletado diretamente pelo poder público municipal, situação diferente com o que ocorre com mais de $14 \%$ das famílias. Cerca de 1.300 famílias descartam seu lixo indevidamente ou é coletado de forma indireta, queimado, jogado em terrenos vazios ou logradouros, no rio, ou em outros locais. O destino desse material é incerto, acarretando um aumento nos problemas ambientais e para saúde já mencionados anteriormente (MDS, 2018).

As condições da estrutura física das residências também são diversas, em $69,1 \%$ das famílias, o material predominante nas paredes externas dos domicílios é de alvenaria/tijolo com revestimento; $19,7 \%$ de alvenaria/tijolo sem revestimento e os outros $11,2 \%$ são de madeira aparelhada, taipa revestida, taipa não revestida, 
madeira aproveitada, palha ou outro material. Em relação ao material predominante no piso das residências, $64,6 \%$ das famílias possuem o piso do domicílio de cerâmica, lajota ou pedra; $29 \%$ de cimento; $1,1 \%$ de terra; $1,4 \%$ de madeira aparelhada; os outros $3,9 \%$ possuem outro tipo de material como piso ou não informaram (MDS, 2018).

Dentre o total de residências, em $84,4 \%$ delas existem calçamento em frente ao seu domicílio, enquanto, $0,7 \%$ possuem calçamento parcial, $11,6 \%$ não existe calçamento algum e 3,2\% não informaram. Quanto ao tipo de iluminação, 58,4\% das residências possuem energia elétrica com medidor próprio; $23,5 \%$ energia elétrica com medidor comunitário; $13,9 \%$ energia elétrica sem medidor, e $4,2 \%$ de outras formas e/ou sem informação (MDS, 2018).

Dessa forma, estes dados mostram as fragilidades em que as famílias atendidas pelo PBF no município se encontram, reafirmando que a renda é apenas uma dimensão da pobreza, já que as condições de moradia da população são deficitárias. Além disso, a grande quantidade de famílias caracterizadas em estado de extrema pobreza, não permitem intervenções próprias em seu local de moradia e entorno, o que dificulta ainda mais a vida das pessoas e impactam significativamente na formação da identidade desses sujeitos.

\section{CONSIDERAÇÕES FINAIS}

O objetivo deste texto foi discutir as características da população atendida pelo Programa Bolsa Família em Piracicaba. Apesar de parecer exaustivo quanto ao detalhamento das condições de vida da população por meio da caracterização dos domicílios, faz-se necessário fazê-la, principalmente, pela falta de levantamento e sistematização dessas informações como um aporte científico de discussão e para tomada de decisão no nível municipal. Raras são as publicações sobre o Bolsa Família em Piracicaba, além dos dados não serem abertamente apresentados pela gestão municipal local.

Tal prerrogativa não é exclusiva para o município de Piracicaba, há uma necessidade de bibliografias que utilizem os dados do Cadastro Único de forma geral, utilizando todas as pessoas e famílias de menor renda cadastradas ou de forma mais específica, como o realizado com um recorte pelo Bolsa Família. O uso de tal ferramenta (o Cadúnico) traz uma possibilidade de analisar as condições de vida da população brasileira de forma muito detalhada, sendo fundamental que novas pesquisas sejam realizadas utilizando os dados contidos nessa ferramenta.

Para o poder público municipal (bem como para a análise e divulgação científica) o uso do Cadúnico está além de ser uma plataforma para programas de distribuição de renda. Deve ser vista como uma potencial fonte para o conhecimento do território e a proposição de políticas públicas para a população. Sendo assim, através dos dados dispostos, é possível propor políticas variadas para uma população com alto grau de vulnerabilidade econômica, social e ambiental (como mostrado pelos dados) com políticas de redistribuição de renda aliada à requalificação urbana.

Os resultados mostraram que a maioria das famílias atendidas pelo PBF em Piracicaba apresentam condições de extrema pobreza, isto é, $70 \%$ do total de famílias. Além disso, as condições de moradia são precárias, com falta de banheiro, coleta de esgoto e de lixo, o que acarreta o descarte irregular desses resíduos, impactando significativamente o meio ambiente.

Os desafios a serem enfrentados no uso dos dados utilizados nesta pesquisa são muitos e se dão em diversos âmbitos: a começar pelo Cadastro Único que, apesar 
do seu potencial de conhecimento das características da população, necessita de constante atualização do seu banco de dados e para isso o poder público municipal e as famílias têm papéis fundamentais na manutenção desse banco de dados. Portanto, deve-se sempre ser estimulada a presença das famílias nos centros de coleta e atualização de dados.

A divulgação dos dados do Cadúnico é outro fator, já que para garantir a confidencialidade das informações, não são divulgados os endereços das famílias cadastradas ou beneficiadas por algum programa social, o que dificulta análises científicas relacionando a distribuição espacial da população com a oferta de serviços públicos, empregos, lazer, infraestrutura, entre outros.

Ademais, como os dados são por autodeclaração das condições de vida e características da população, pode haver algumas distorções na hora da coleta dos dados, 0 que pode dificultar $o$ tratamento $e$ análise dessas informações. Principalmente, devido ao alto índice de não resposta em algumas perguntas do questionário, dificultando uma compreensão mais integrada sobre as condições de vidas das famílias.

\section{REFERÊNCIAS BIBLIOGRÁFICAS}

ALVES, J. D. G. DISPERSÃO URBANA E A ATUAÇÃO DO MERCADO IMOBILIÁRIO EM CIDADES MÉDIAS: REFLEXÕES A PARTIR DA CIDADE DE PIRACICABA/SP. GEOFRONTER, v. 2, p. 104-124, 2019

BRASIL. DECRETO № 6.135, DE 26 DE JUNHO DE 2007. Dispõe sobre o Cadastro Único para Programas Sociais do Governo Federal e dá outras providências. Brasília, 2007.

CAVALCANTI, D. M.; COSTA, E. M.; SILVA, J. L. M. PROGRAMA BOLSA FAMÍLIA E O NORDESTE: IMPACTOS NA RENDA E NA EDUCAÇÃO, NOS ANOS DE 2004 e 2006. Rev. Econ. Contemp., Rio de Janeiro, v. 17, n. 1, p. 99-128, jan-abr/2013.

COSTA, S. A. GESTÃO DO CADÚNICO E DO PROGRAMA BOLSA FAMÍLIA: desafios para a universalização do acesso e cobertura do benefício em Barueri, SP. Revista NAU Social - v.7, n.13, p. 31-42 Nov 2016 / Abr 2017.

EMPRESA PAULISTA DE PLANEJAMENTO METROPOLITANO - EMPLASA. Aglomeração urbana de Piracicaba. 2017. Disponível em <https://www.emplasa.sp.gov.br/AUP>. Acessado em: 10/01/2018.

FAHEL, M. C. X.; MORAIS, T.; FRANÇA, B. C. O impacto do Bolsa Família na inclusão educacional: análise da matricula escolar em Minas Gerais. Anais do I Circuito de Debates Acadêmicos, IPEA, 2011.

FARIAS, L.; DIAS, R. B. O CADASTRO ÚNICO: A CONSOLIDAÇÃO DE UMA INFRAESTRUTURA PARA PROGRAMAS SOCIAIS. Anais da XI Jornada Latinoamericanas de estudos sociais da ciência e da tecnologia, UTFRP, Curitiba, 2016.

GLEWWE, P.; A. L. KASSOUF. The Impact of the Bolsa Escola/Familia Conditional Cash Transfer Program on Enrollment, Drop Out Rates and Grade 
Promotion in Brazil. Department of Applied Economics, University of Minnesota, 2008.

HARVEY, D. O Novo Imperialismo. São Paulo: Loyola, 2004, 201p

INSTITUTO BRASILEIRO DE GEOGRAFIA E ESTATÍSTICA. Dados gerais por município - Piracicaba. Disponível em:

https://cidades.ibge.gov.br/painel/painel.php?codmun=353870. Acessado em: 15/01/2018.

INSTITUTO DE PESQUISAS E PLANEJAMENTO DE PIRACICABA. LOCALIZAÇÃO, RELEVO E EXTENSÃO TERRITORIAL DE PIRACICABA, IPPLAP, 2015.

KAGEYAMA, A; HOFFMANN, R, Pobreza no Brasil: uma perspectiva multidimensional. Revista Economia e Sociedade, Campinas, v, 15, n, 1 (26), p, 79 112, jan,/jun, 2006.

MARICATO, E. Para entender a crise urbana. Ed. Expresso popular, São Paulo, 2015.

MINISTERIO DO DESENVOLVIMENTO SOCIAL. Cartilha do Programa Bolsa Família: transferência de renda e apoio à família no acesso à saúde, à educação e à assistência social. Brasília, 2015.

MINISTERIO DO DESENVOLVIMENTO SOCIAL. Evolução do pagamento do Bolsa Família no Brasil - 2003 a 2016. Disponível em: http://mds.gov.br/area-deimprensa/dados. Acessado em: 17/01/2018.

MINISTERIO DO DESENVOLVIMENTO SOCIAL. Matriz de Informação Social. Disponível em: https://aplicacoes.mds.gov.br/sagi/cecad/tabulador tabcad.php?

Acessado em: 10/01/2018.

LOUREIRO, A. O. F. Uma análise da pobreza no Ceará a partir dos dados do Cadúnico. Textos para Discussão do Instituto de Pesquisa e Estratégia Econômica do Ceará (IPECE), 2007.

RAVAIOLI, P. F. O impacto do Programa Bolsa Família na posse de bens duráveis. Dissertação. Programa de Pós-Graduação em Ciências. Universidade de São Paulo (USP), Piracicaba, 2018.

SOUZA, T. A. A.; COUTO, A. C. L. Programa Bolsa Família: características e perfil da pobreza entre os beneficiários nos estados do Paraná e Bahia. INFORME GEPEC (ONLINE), v. 19, p. 41-56, 2015.

SOUZA, P. H. G. F. et al. OS EFEITOS DO PROGRAMA BOLSA FAMÍLIA SOBRE A POBREZA E A DESIGUALDADE: UM BALANÇO DOS PRIMEIROS QUINZE ANOS. Texto para Discussão 2.499, Ipea, Brasília, 2019.

SOUZA, P. H. G. F.; OSÓRIO, R. G. Perfil da pobreza na Bahia e sua evolução no período 2004-2009. Texto para Discussão 1.743, Ipea, Brasília, 2012. 